\title{
QUALIDADE E APROVEITAMENTO DA ÁGUA DE CHUVA
}

\author{
L. G. PINHEIRO* e A. L. C. ARAÚJo \\ Instituto Federal de Educação, Ciência e Tecnologia do Rio Grande do Norte \\ lidiane.gpinheiro@yahoo.com.br ${ }^{*}$
}

Artigo submetido em 22/09/2015 e aceito em 13/12/2016

DOI: $10.15628 /$ holos.2016.3431

\section{RESUMO}

O aumento no consumo de água interfere diretamente na disponibilidade dos recursos hídricos, sendo a tecnologia uma forte aliada para minimizar tais problemas. O aproveitamento de água de chuva é uma alternativa para minimizar o consumo, porém é importante que sejam feitos estudos para avaliar a sua qualidade. $O$ presente artigo tem como objetivo investigar a possibilidade de coleta e aproveitamento de água de chuva no Campus Natal Central do IFRN. As coletas foram realizadas entre março e junho de 2015 e analisados os 5 primeiros milímetros de chuva a fim de comparar sua qualidade quanto aos padrões físicoquímicos e microbiológicos. Os parâmetros físico- químicos apresentaram uma redução das concentrações ao longo do tempo de chuva, porém quanto aos parâmetros microbiológicos todas as amostras demonstraram-se positivas para coliformes totais e $E$. coli. Desta forma, a água de chuva apresenta grande potencial em ser utilizada para fins não potáveis no Campus Central do IFRN e seu aproveitamento oferece benefícios sociais, ambientais e econômicos. Além dos fins não potáveis, tratamentos simples podem ser empregados para que a água de chuva seja utilizada para outras finalidades, porém é importante que sejam feitos estudos mais detalhados para analisar a qualidade hídrica.

PALAVRAS-CHAVE: Água de chuva, qualidade hídrica, potabilidade.

\section{QUALITY AND UTILIZATION OF RAINWATER}

\begin{abstract}
The increase in water consumption interferes directly in the availability of water resources, and the technology is a strong ally to minimize such problems. The employment of rainwater is an alternative to minimize consumption, but it is important to study and evaluate its quality. This article aims to investigate the possibility of collection and better utilization of rainwater at IFRN Central Campus Natal. The collections were taken between March and June 2015 and analyzed the first $5 \mathrm{~mm}$ of rain in order to compare their quality regarding to physicochemical and microbiological parameters. The physicochemical parameters showed a reduction in their
\end{abstract}

indices along the rain, but the microbiological parameters showed positive results for total coliforms and $E$. coli in all the samples. Thus, the rainwater has great potential to be used for non-potable purposes in the Central Campus of IFRN and its utilization offers social, environmental and economic benefits. In addition to the non-potable purposes, simple treatments may be employed for rainwater to be used for other purposes, but it is important that more detailed studies are made to analyze the water quality.

KEYWORDS: Rainwater, water quality, potability 


\section{INTRODUÇÃO}

O crescimento populacional acentuado, atrelado à expansão das indústrias e da agricultura, influencia diretamente o aumento do consumo de água, o que vem a afetar a disponibilidade dos recursos hídricos, provocando muitas vezes sua escassez. Os esforços em busca de soluções para minimizar tais problemas, auxiliando em seu manejo e aproveitamento, têm a tecnologia como importante aliada. Cientistas trabalham atualmente no desenvolvimento de equipamentos, sistemas e métodos que atuem potencializando os recursos hídricos disponíveis, contribuindo para reduzir seu estágio de degradação (SILVA e DOMINGOS, 2007).

O uso racional dos recursos hídricos, com a reciclagem da água, eliminação de desperdícios, reaproveitamento de águas servidas e das águas de chuva, representam economia de recursos uma vez que contribui para redução do volume e da demanda de água tratada, favorecendo a proteção do recurso natural (LUZ, 2005).

Devido às suas características com predomínio dos climas tropical e equatorial, o Brasil recebe um significativo volume de chuva por ano (TOMAZ, 2003). Neste contexto tem destaque toda a faixa litorânea do país que inclui a cidade de Natal/RN com altos índices pluviométricos, característica essa que favorece a captação de água de chuva e o aproveitamento deste recurso. De acordo com Silva e Domingos (2007), a água de chuva pode ser utilizada facilmente para fins não potáveis, devendo passar por uma série de processos de tratamento para atingir os padrões de potabilidade. Dentre as técnicas de aproveitamento da água, destaca-se a água de chuva coletada em telhados, a qual apresenta grande potencial para ser utilizada para as mais variadas finalidades, podendo atuar na substituição da água potável para usos menos nobres, tais como a descarga em vasos sanitários, lavagem de carros, limpeza de pisos e calçadas, além da irrigação de jardins e campos de futebol.

Apesar da sua extensa possibilidade de uso, a qualidade da água pluvial traz preocupações no que diz respeito ao seu aproveitamento. De um modo geral a água proveniente das chuvas apresenta boas condições, passando por um processo de "destilação natural", a qual está relacionada ao ciclo hidrológico, aos processos de evaporação e condensação (SILVA e DOMINGOS, 2007). Porém, as águas pluviais podem carrear contaminantes, uma vez que a água da chuva lava o ar de todos os poluentes em suspensão, tais como poeira, óxidos de enxofre e nitrogênio, metano, hidrocarbonetos e metais, deixando de ser potável, mas apresentando ainda grande potencial ao ser direcionada como fonte complementar (CAMDESSUS et al., 2005).

Desta forma, sabendo-se que a qualidade da água varia ao longo do tempo de chuva, uma vez que ao atravessar a atmosfera e entrar em contato com os telhados pode carrear impurezas, destaca-se a importância de estudos e análises da qualidade de água de chuva para fins de aproveitamento. $\mathrm{O}$ presente artigo tem como objetivo investigar a possibilidade de coleta e aproveitamento de água de chuva no Campus Natal Central do Instituto Federal de Educação, Ciência e Tecnologia do Rio Grande do Norte (IFRN). 


\section{METODOLOGIA}

A pesquisa foi desenvolvida no campus central do IFRN, localizado em Natal, Rio Grande do Norte. A cidade do Natal, situada no litoral do estado, apresenta precipitações pluviométricas durante todo o ano, com ocorrência dos maiores índices de chuva nos meses de março, junho e julho no ano de 2015 (BRASIL, 2015).

Inicialmente foi delimitada a área de telhado, composto por telhas de amianto, por meio do qual seria coletada a água proveniente das chuvas, e a partir daí foram instalados, em conexão com as calhas coletoras, os reservatórios para coleta e armazenamento da água. Os reservatórios dizem respeito a 05 (cinco) tubos compostos por canos em policloreto de vinila (PVC) de $100 \mathrm{~mm}$ de diâmetro interconectados de forma que após o preenchimento por completo de cada tubo, a água é direcionada aos tubos subsequentes até o preenchimento total do sistema, e seu direcionamento ao extravasor. Cada um dos tubos é equipado com uma torneira em sua parte inferior para que seja feita a coleta da água de chuva de forma independente em cada um deles (Figura 1).
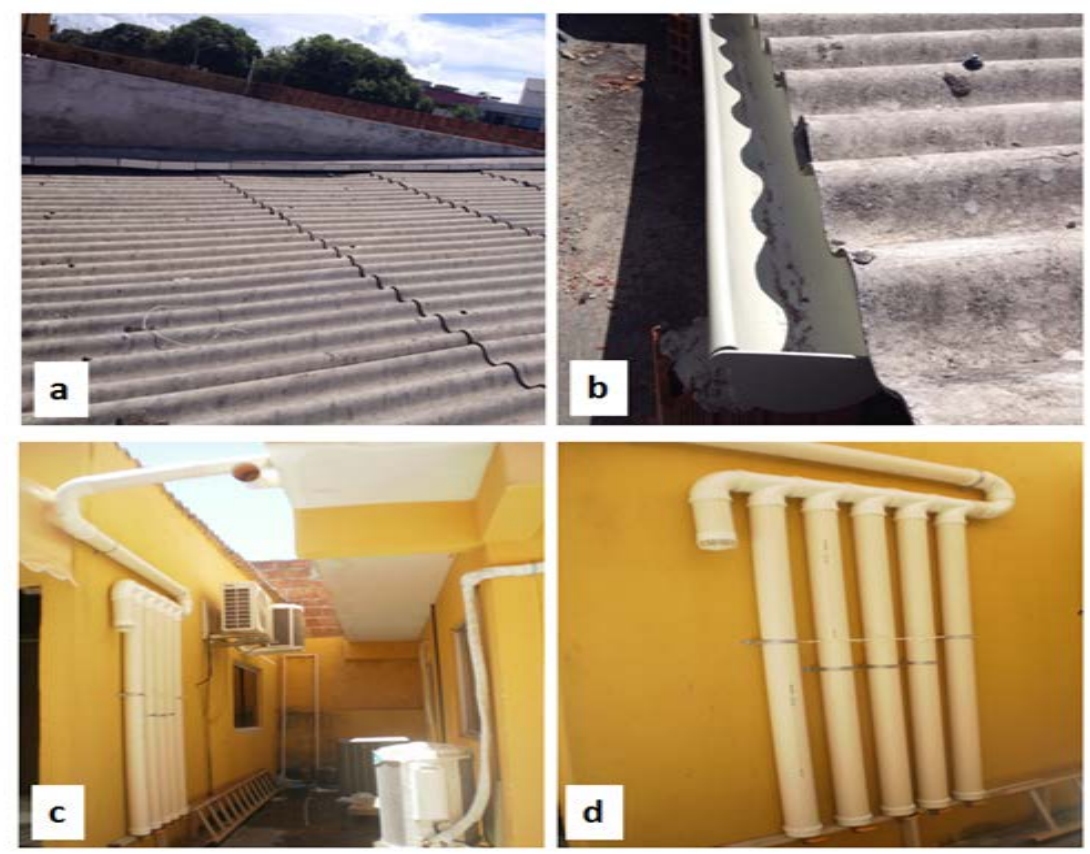

Figura 1: Sistema para coleta de água de chuva. a) área de telhado, b) calha coletora, c) conexão entre telhado e sistema de captação, d) sistema de coleta em tubos de PVC.

A superfície escolhida para instalação do sistema apresenta uma área total de $15 \mathrm{~m}^{2}$. Sabendo-se que o tamanho em metros quadrados $\left(\mathrm{m}^{2}\right)$ da superfície do telhado diz respeito à quantidade em litros de água de chuva coletada, o que corresponde a $1 \mathrm{~mm}$ de precipitação, cada tubo instalado tem a capacidade de armazenamento de 15 litros que correspondem a cada milímetro de água de chuva. Desta forma, sendo instalados 05 tubos, foi possível a coleta dos 05 primeiros milímetros de chuva, proporcionando a análise da água e sua composição ao longo do tempo de chuva (Figura 2). 


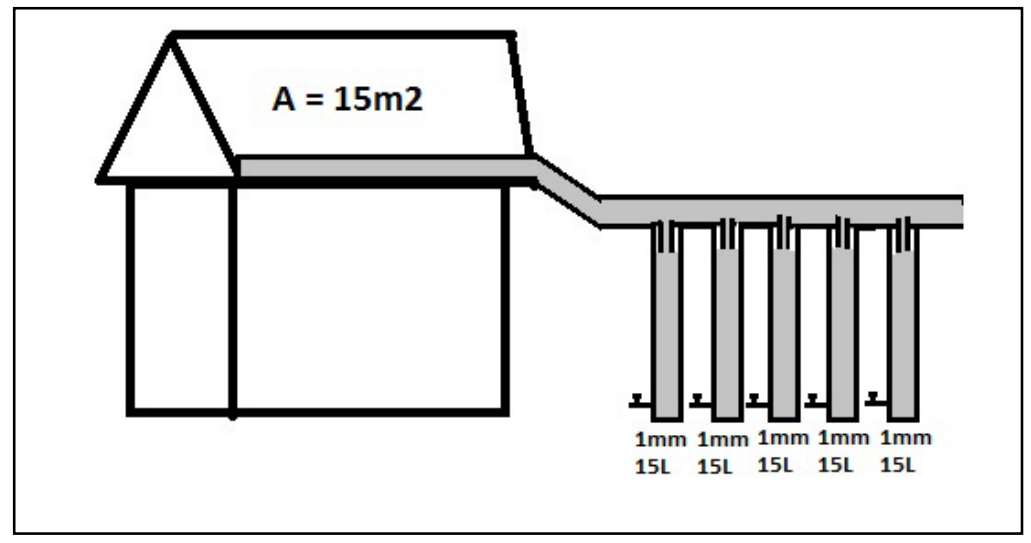

Figura 2: Esquema de coleta e armazenamento da água de chuva.

A coleta da água foi realizada no período compreendido entre os meses de março e junho de 2015, tendo sido feita após cada chuva e coletadas amostras de cada um dos tubos que compõem o sistema. A partir daí a água foi encaminhada para os laboratórios de Físico-Química e Microbiologia da Diretoria Acadêmica de Recursos Naturais do IFRN, onde foram feitas as análises físico-químicas e microbiológicas, por meio das quais foi verificada a qualidade da água e apresentadas sugestões de aproveitamento para atividades variadas no Campus.

Quanto à coleta destinada às análises físico-químicas, a água de chuva foi armazenada em garrafas de polietileno com capacidade para 1,5 litros mantidos sob refrigeração a 4 으 $\mathrm{e}$ analisadas em um prazo máximo de 72 horas após a coleta. Com relação aos parâmetros, a qualidade da água foi analisada físico-quimicamente quanto a sua cor, turbidez, sólidos totais dissolvidos (STD), pH, alcalinidade, cloreto e condutividade.

No que diz respeito ao procedimento de coleta para análises microbiológicas, a mesma foi feita em frascos de vidro tipo pyrex com capacidade para $250 \mathrm{~mL}$ previamente esterilizados e com os cuidados necessários a fim de não serem contaminados, sendo a análise feita imediatamente. Foi então utilizado o método do substrato cromogênico por meio do protocolo Colilert, através do qual pôde ser evidenciada a presença ou ausência de coliformes nas amostras de água coletadas. Neste tipo de análise, o reagente é adicionado nas amostras e estas são incubadas a uma temperatura de 35 ㄷ por um período de $24 \mathrm{~h}$ e a mudança de coloração indica contaminação por coliformes totais ou fecais. As amostras que desenvolvem coloração amarela escura indicam resultado positivo para coliformes totais e as que apresentam fluorescência quando submetidas à luz ultravioleta (UV-A) a 365nm, indicam contaminação por coliformes fecais ( $E$. coli).

Quanto aos parâmetros físico-químicos foram analisadas as águas provenientes de sete dias de chuva e quanto aos parâmetros microbiológicos foram analisadas as águas de três dias de chuva, totalizando assim dez dias de coleta de água, sendo cada coleta composta por cinco amostras, em cada coluna consecutivamente, as quais dizem respeito aos cinco primeiros milímetros de chuva.

Após as análises laboratoriais os valores obtidos foram comparados aos exigidos pela Portaria MS N² 2914/2011 (BRASIL, 2011), a qual dispõe sobre os procedimentos de controle e de vigilância da qualidade da água para consumo humano e seu padrão de potabilidade, a fim de 
analisar sua viabilidade de utilização com base em suas características físico-químicas e microbiológicas.

\section{RESULTADOS E DISCUSSÕES}

A qualidade da água de chuva foi avaliada quanto aos seus parâmetros físico-químicos e microbiológicos. A média dos resultados obtidos nas análises físico-químicas das amostras de água de chuva está apresentada na Tabela 1 e as Figuras de 3 a 8 apresentam os resultados de cada amostragem.

Tabela 1: Resumo estatístico das variáveis monitoradas ao longo das precipitações.

\begin{tabular}{l|l|l|l|l|l|l|l|l}
\hline $\begin{array}{l}\text { Precipitação } \\
(\mathrm{mm})\end{array}$ & $\begin{array}{l}\text { Condutividade } \\
(\mu \mathrm{S} / \mathrm{cm})\end{array}$ & $\begin{array}{l}\text { STD } \\
(\mathrm{mg} / \mathrm{L})\end{array}$ & $\mathrm{pH}$ & $\begin{array}{l}\text { Cloreto } \\
(\mathrm{mg} / \mathrm{L})\end{array}$ & $\begin{array}{l}\text { Cor } \\
(\mathrm{uH})\end{array}$ & $\begin{array}{l}\text { Turbidez } \\
(\mathrm{uT})\end{array}$ & $\begin{array}{l}\text { Alcalinidade } \\
\left(\mathrm{mgCaCO}_{3} / \mathrm{L}\right)\end{array}$ \\
\hline \multirow{4}{*}{$1 \mathrm{~mm}$} & Média & 111,4 & 54,8 & 7,1 & 1,5 & 17,8 & 13,8 & 47,3 \\
\cline { 2 - 9 } & DP & 34,9 & 16,9 & 0,4 & 1,5 & 11,0 & 16,4 & 18,1 \\
\cline { 2 - 9 } & CV & 31,4 & 30,9 & 5,6 & 100,0 & 61,9 & 119,2 & 38,3 \\
\hline \multirow{4}{*}{$2 \mathrm{~mm}$} & Média & 84,1 & 41,6 & 7,1 & 0,9 & 8,1 & 2,9 & 36,0 \\
\cline { 2 - 9 } & DP & 9,9 & 4,7 & 0,1 & 1,1 & 3,0 & 1,6 & 2,6 \\
\cline { 2 - 9 } & CV & 11,7 & 11,3 & 2,0 & 119,6 & 36,9 & 54,1 & 7,2 \\
\hline \multirow{4}{*}{$3 \mathrm{~mm}$} & Média & 74,2 & 36,8 & 7,2 & 0,2 & 8,9 & 3,6 & 33,3 \\
\cline { 2 - 9 } & DP & 16,3 & 8,1 & 0,2 & 0,4 & 2,8 & 2,4 & 5,8 \\
\cline { 2 - 9 } & CV & 21,9 & 21,9 & 3,0 & 223,6 & 31,6 & 65,5 & 17,5 \\
\hline \multirow{4}{*}{$4 \mathrm{~mm}$} & Média & 68,8 & 34,2 & 7,2 & 0,1 & 8,2 & 2,9 & 32,7 \\
\cline { 2 - 9 } & DP & 13,8 & 6,8 & 0,3 & 0,2 & 4,6 & 1,5 & 4,1 \\
\cline { 2 - 9 } & CV & 20,0 & 19,9 & 3,9 & 223,6 & 56,1 & 53,0 & 12,6 \\
\hline \multirow{5}{*}{$5 \mathrm{~mm}$} & Média & 64,8 & 32,1 & 7,1 & 0,0 & 8,9 & 2,7 & 30,0 \\
\cline { 2 - 8 } & DP & 14,3 & 6,9 & 0,2 & 0,0 & 6,8 & 2,0 & 5,7 \\
\cline { 2 - 8 } & CV & 22,0 & 21,6 & 3,4 & ND & 76,4 & 74,0 & 18,9 \\
\hline
\end{tabular}

DP - desvio padrão; CV - coeficiente de variação; ND - não determinado

A cor é uma alteração decorrente da presença de matéria orgânica ou inorgânica na água. Os valores de cor obtidos nas amostras analisadas estão apresentados na Figura 3.

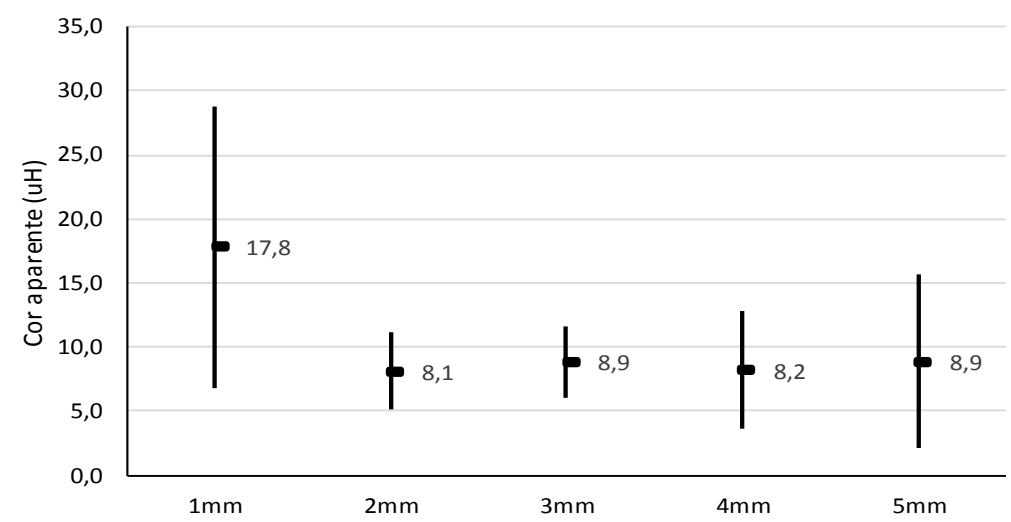

Figura 3: Valores de cor obtidos nos cinco primeiros milímetros de chuva (média \pm DP). 
Nas amostras analisadas observa-se um índice de cor mais elevado no primeiro milímetro de água de chuva coletada, próximo aos $18 \mathrm{uH}$, havendo uma diminuição desse parâmetro ao longo do tempo de chuva. Tais variações também foram observadas por Hagemann (2009) em seus estudos, nos quais verificou valores mais elevados nas primeiras amostras de água, os quais apresentaram decréscimo nas amostras seguintes.

Com relação ao parâmetro da turbidez, provocado por materiais em suspensão, o mesmo representa uma expressão da propriedade óptica que faz com que a luz seja espalhada e absorvida, não se transmitindo em linha reta (PARRON et al., 2011). O primeiro milímetro de chuva apresentou um alto índice de turbidez, próximo a 14 NTU, havendo diminuição nos valores do parâmetro ao longo dos milímetros de chuva analisados (Figura 4).

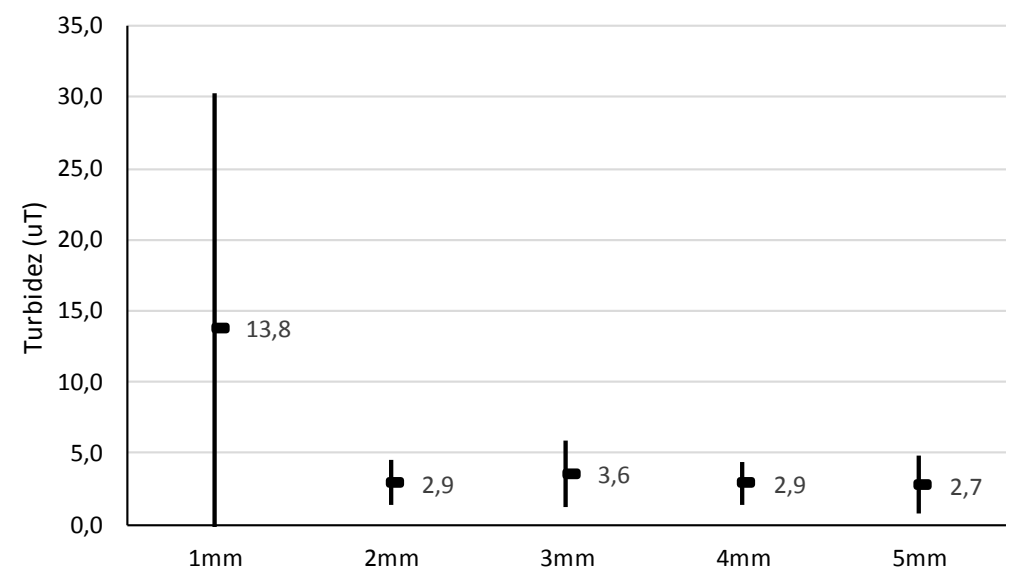

Figura 4: Valores de turbidez obtidos nos cinco primeiros milímetros de chuva (média \pm DP).

Estudos realizados por Calheiros et al. (2014) também apresentaram variações quanto a este parâmetro, havendo uma redução nos valores ao longo do tempo de chuva. Tal redução pode ser explicada devido ao fato da chuva ser responsável por lavar as impurezas presentes na superfície dos telhados, as quais interferem diretamente nas características da água, inclusive na turbidez.

Os sólidos totais dissolvidos (STD), soma dos constituintes químicos dissolvidos na água, medem a concentração de substâncias iônicas (PARRON et al., 2011). De acordo com o gráfico (Figura 5), observa-se que o primeiro milímetro de água coletada apresentou valores mais elevados no que diz respeito aos STD, na faixa dos $55 \mathrm{mg} / \mathrm{L}$, havendo uma diminuição gradativa desses valores nas amostras seguintes. 


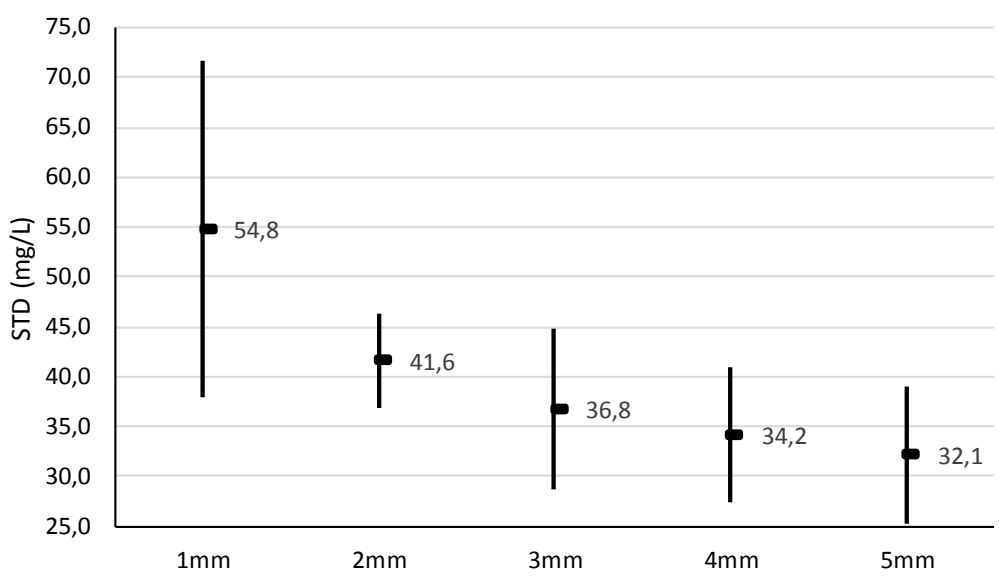

Figura 5: Valores de sólidos totais dissolvidos obtidos nos cinco primeiros milímetros de chuva (média \pm DP).

Assim como no presente estudo, Hagemann (2009) também evidenciou a redução nos valores de sólidos totais dissolvidos no decorrer das precipitações, tendo ocorrido também um maior decréscimo das concentrações entre a primeira e a segunda amostra e mais gradual nas amostras seguintes.

$\mathrm{O}$ pH (potencial hidrogeniônico) é uma grandeza que indica o teor de alcalinidade, neutralidade ou acidez de uma solução. Nas amostras analisadas o pH se apresentou levemente básico, geralmente entre 7,1 (Figura 6). Valores semelhantes foram encontrados por Calheiros et al. (2014) em seus estudos, nos quais o valor de pH da água de chuva coletada diretamente foi de $5,81 \pm 0.34$, o qual sofreu aumento após passar por superfícies de telhados de amianto, apresentando a partir daí valores médios de pH de $7.36 \pm 0.44$. De acordo com Tomaz (2003), o pH da água de chuva apresenta-se sempre ácido na atmosfera variando entre 4,5 e 5,8, e após entrar em contato com o telhado aumenta para uma média de 6,5, variando de acordo com o material constituinte da superfície do telhado.

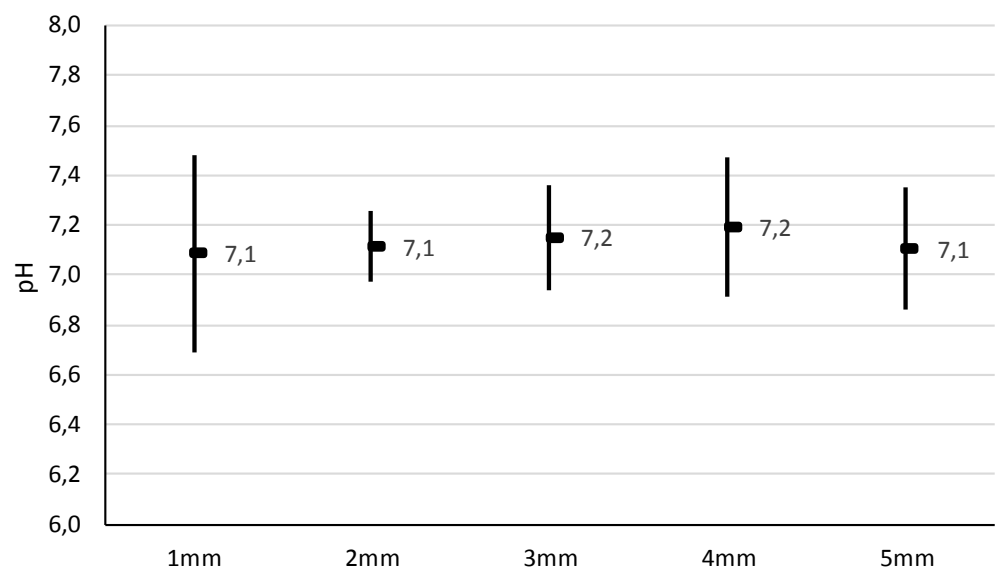

Figura 6: Valores de pH obtidos nos cinco primeiros milímetros de chuva (média \pm DP).

Os valores de $\mathrm{pH}$ apresentados pelas amostras de água analisadas encontram-se, portanto, dentro da normalidade, de forma que o pequeno aumento observado nos $3^{\circ}$ e $4^{\circ}$ milímetros de 
chuva não representa uma variação significativa e o mesmo pode ser ocasionado por alterações na intensidade da chuva e/ou do vento.

A alcalinidade, capacidade da água em neutralizar ácidos (PARRON et al., 2011), também apresentou uma diminuição em seus valores ao longo do tempo de chuva, conforme pode ser observado na Figura 7.

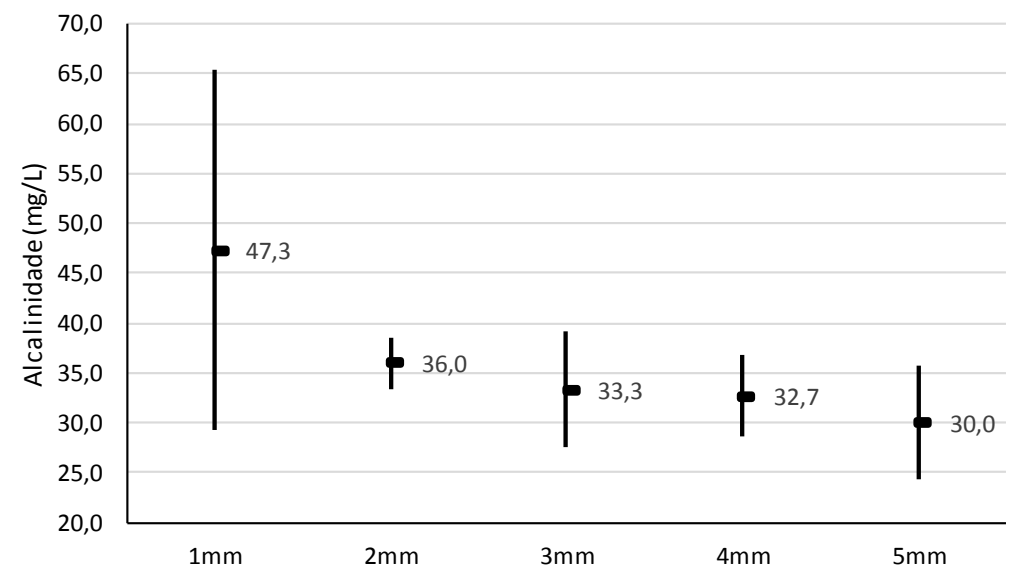

Figura 7: Valores de alcalinidade obtidos nos cinco primeiros milímetros de chuva (média \pm DP).

Em seus estudos, Calheiros et al. (2014) também obtiveram valores semelhantes, nos quais a alcalinidade apresentou valores médios de $40.80 \pm 8.80 \mathrm{mgCaCO} / \mathrm{L}^{-1}$ após escorrer sobre a superfície de telhado de amianto, comportamento já esperado devido aos valores obtidos por meio das análises de $\mathrm{pH}$.

A condutividade, segundo Parron et al. (2011) refere-se à capacidade de condução de corrente elétrica apresentada por uma solução aquosa. Os valores da condutividade elétrica estão apresentados na Figura 8.

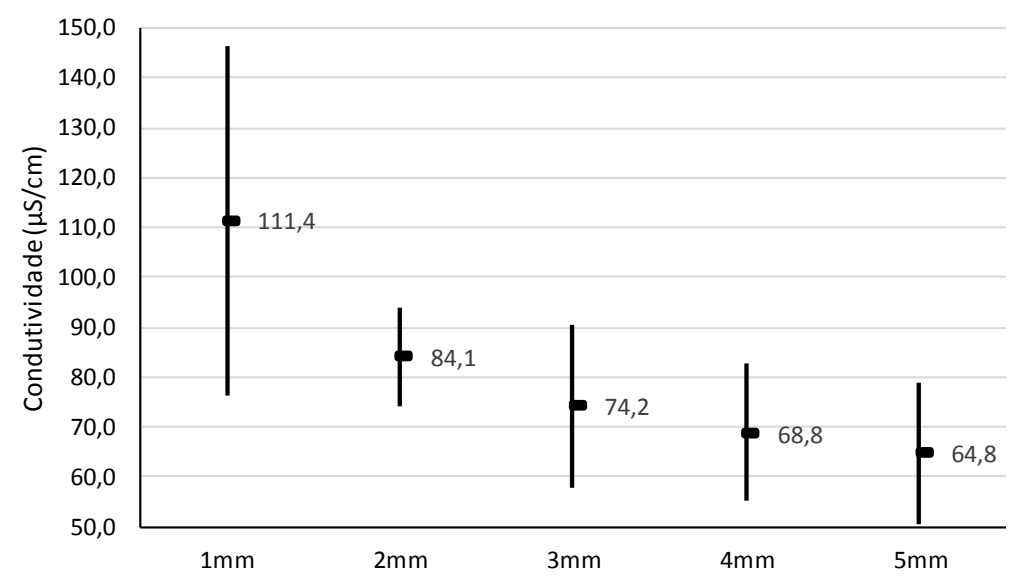

Figura 8: Valores da condutividade elétrica obtidos nos cinco primeiros milímetros de chuva (média $\pm D P$ ).

A condutividade, conforme observado na Figura 8, variou entre 111 e $65 \mu \mathrm{S} / \mathrm{cm}$ aproximadamente, semelhantemente aos resultados obtidos por Calheiros et al. (2014) para 
telhas de amianto, com valores entre 63.2 e $108.8 \mu \mathrm{S} / \mathrm{cm}^{-1}$. Constata-se, portanto, um declínio nos valores da condutividade elétrica ao longo do tempo de chuva.

Por fim foi analisado o cloreto, o qual diz respeito a um dos principais ânions inorgânicos presentes na água (PARRON et al., 2011). Nas amostras analisadas, este parâmetro alcançou um valor máximo de cerca de $1,5 \mathrm{mg} / \mathrm{L}$ no 10 milímetro de chuva, sofrendo decaimento ao longo do tempo de chuva, apresentando valores iguais a $0 \mathrm{mg} / \mathrm{L}$ a partir do $29 \mathrm{~mm}$ na maioria das amostras. Tais resultados apresentam-se em uma faixa relativamente baixa quando comparados por exemplo aos trabalhos desenvolvidos por Hagemann (2009), por meio dos quais foram obtidas médias deste parâmetro variando entre 3,2 e $7,4 \mathrm{mg} / \mathrm{L}$.

Assim, de modo geral observa-se que os parâmetros físico-químicos analisados tiveram uma redução em seus índices ao longo do tempo de chuva, o que demonstra uma melhoria em sua qualidade. Conforme apresentado por Tomaz (2003), as características e a composição da água da chuva podem variar de acordo com a localização geográfica do ponto de amostragem e com as condições meteorológicas, tais como estação do ano, intensidade e duração da chuva, além de sofrer interferências da poluição atmosférica. Em seus estudos, Melo (2007) analisou a qualidade da água com base na variação dos parâmetros físico-químicos ao longo do tempo de chuva em diferentes regiões da cidade de Natal e observou grande redução dos valores em regiões com maior concentração urbana, principalmente entre o primeiro e segundo milímetros e uma redução mais gradativa, porém ainda existente em áreas com poucas fontes de poluição. Tal redução aponta para o fato de os primeiros milímetros de chuva serem responsáveis pela lavagem da atmosfera e dos telhados, carreando assim grande quantidade de poluentes.

Quanto aos parâmetros microbiológicos analisados, todas as amostras apresentaram resultados positivos para coliformes totais e $E$. coli, o que indica contaminação por fezes de animais de sangue quente, tais como pássaros e gatos, nas águas de chuva analisadas.

Segundo Tomaz (2003), os coliformes fecais são os mais importantes parâmetros no que diz respeito à contaminação biológica. Os coliformes são utilizados como indicadores indiretos de patógenos, uma vez que sua presença indica a existência de fezes no meio analisado e além da $E$. coli podem estar presentes também bactérias potencialmente patogênicas. Tal contaminação, de acordo com Calheiros et al. (2014), deve-se possivelmente à contaminação da superfície do telhado onde foi realizada a coleta.

A qualidade da água de chuva pode sofrer alteração em seus parâmetros devido a poluição do ar, contato com animais, presença de matéria orgânica ou até mesmo pelo material pela qual escorre, de forma que o material que compõe os sistemas de coleta de águas pluviais pode modificar a qualidade e o destino final das águas (CALHEIROS et al., 2014; LADE et al., 2013).

Após as análises físico-químicas e microbiológicas da água de chuva coletada, os resultados obtidos foram então comparados com a legislação nacional a fim de se estabelecer seus melhores usos. No que diz respeito ao padrão de potabilidade, a Tabela 2 apresenta os parâmetros analisados e os resultados obtidos, de acordo com a Portaria N²914/2011 (BRASIL, 2011).

Tabela 2: Comparação entre os resultados obtidos e os padrões de potabilidade da água vigentes no Brasil 


\begin{tabular}{l|l|l|l|l|l|l}
\hline & \multicolumn{5}{c}{ Média da precipitação } \\
\hline Parâmetros & $\begin{array}{l}\text { Limites } \\
\text { permissíveis* }\end{array}$ & $1 \mathrm{~mm}$ & $2 \mathrm{~mm}$ & $3 \mathrm{~mm}$ & $4 \mathrm{~mm}$ & $5 \mathrm{~mm}$ \\
\hline $\begin{array}{l}\text { Condutividade } \\
(\mu \mathrm{S} / \mathrm{cm})\end{array}$ & ND & 111,4 & 84,1 & 74,2 & 68,8 & 64,8 \\
\hline $\mathrm{STD}(\mathrm{mg} / \mathrm{L})$ & 1000 & 54,8 & 41,6 & 36,8 & 34,2 & 32,1 \\
\hline $\mathrm{pH}$ & $6,0-9,5$ & 7,1 & 7,1 & 7,2 & 7,2 & 7,1 \\
\hline Cloreto $(\mathrm{mg} / \mathrm{L})$ & 250 & 1,5 & 0,9 & 0,2 & 0,1 & 0,0 \\
\hline Cor $(\mathrm{uH})$ & 15 & 17,8 & 8,1 & 8,9 & 8,2 & 8,9 \\
\hline Turbidez (uT) & 5 & 13,8 & 2,9 & 3,6 & 2,9 & 2,7 \\
\hline $\begin{array}{l}\text { Alcalinidade } \\
\text { (mgCaCO }\end{array}$ /L) & ND & 47,3 & 36,0 & 33,3 & 32,7 & 30,0 \\
\hline Coliformes totais & Ausência & Presente & Presente & Presente & Presente & Presente \\
\hline E. coli & Ausência & Presente & Presente & Presente & Presente & Presente \\
\hline
\end{tabular}

ND - não determinado; *Portaria 2914/2011

Ao serem comparados os parâmetros físico-químicos analisados com os limites permissíveis para fins de potabilidade, observa-se que de forma geral a água apresenta-se com qualidade satisfatória a partir do segundo milímetro de chuva. Quanto aos parâmetros microbiológicos, porém, de acordo com a portaria os índices de coliformes totais e $E$. coli devem estar ausentes, e nas amostras analisadas ambos os parâmetros apresentaram resultados positivos ao longo dos cinco milímetros de chuva, o que está em desacordo com os padrões de potabilidade estabelecidos pela legislação nacional.

A partir das análises físico-químicas e microbiológicas realizadas, observa-se assim a ocorrência de material externo carreado pelas águas da chuva, o que altera suas características naturais e pode provocar contaminação principalmente nos primeiros milímetros de chuva, provocando assim a ocorrência dos valores fora dos padrões de potabilidade. Tomaz (2003) aborda em seus estudos que microrganismos provenientes do telhado e encanamentos podem se desenvolver nos reservatórios de água de chuva, sendo aconselhado o uso da água apenas para fins não potáveis, tais como descargas de vasos sanitários, irrigação de jardins e lavagem de calçadas. Destaca-se assim, a importância do descarte dos primeiros milímetros de chuva, sendo aconselhado que a primeira água responsável pela lavagem da superfície dos telhados seja desprezada e jogada fora, devido à possibilidade de contaminação. (TOMAZ, 2003).

\section{CONCLUSÃO}

Dessa forma, a partir da avaliação da qualidade da água de chuva, observa-se que a mesma apresenta grande potencial em ser utilizada para fins não potáveis no Campus Central do IFRN, bem como em outras localidades que apresentem altas taxas de pluviosidade. $\mathrm{O}$ aproveitamento desse recurso oferece benefícios de cunho econômico, social e ambiental, uma vez que promove o reuso de águas que seriam descartadas no ambiente, promovendo redução no que diz respeito às tarifas empregadas em contas de água, além de poder ser armazenada e utilizada por populações que sofrem com irregularidade de chuvas e escassez hídrica e proporcionar redução no consumo 
de água potável, valioso recurso ambiental que deve ser preservado. No que diz respeito ao Campus Central do IFRN, tendo em vista o grande potencial de captação devido às altas taxas pluviométricas, bem como a qualidade físico-química apresentada pelas amostras analisadas, ampliando-se a instalação de calhas, condutores e reservatórios em conexão com as áreas de telhado, a água de chuva pode ser armazenada e utilizada em substituição da água potável para diversas atividades, tais como lavagem das calçadas e irrigação dos jardins da instituição. Apesar disso, é importante salientar a necessidade do descarte dos primeiros milímetros de chuva, de forma que não seja utilizada a parcela da água com maior concentração de poluentes. Além dos fins menos nobres apresentados, tratamentos simples como por exemplo a cloração, podem ser empregados para que as águas provenientes das chuvas sejam utilizadas para outras finalidades. Destaca-se assim a importância da realização de estudos mais detalhados de forma a analisar a qualidade hídrica, incluindo a comparação dos parâmetros da água de chuva coletada diretamente da atmosfera com amostras coletadas a partir do escoamento de telhados, bem como o uso de pastilhas de cloro no tratamento de desinfecção da água.

\section{REFERÊNCIAS}

1. Portaria MS no 2914, de 12 de dezembro de 2011. Dispõe sobre os procedimentos de controle e de vigilância da qualidade da água para consumo humano e seu padrão de potabilidade. Recuperado de http://www.saude.mg.gov.br/images/documentos/PORTARIA\%20No\%202.914,\%20DE\%2012\%20DE\%20DEZEMBRO\%20DE\%202011.pdf

2. Ministério da Agricultura, Pecuária e Abastecimento. (2015). Instituto Nacional de Meteorologia. Chuva acumulada mensal na estação automática: Natal (RN). Recuperado em $08 \quad$ setembro, 2015, de http://www.inmet.gov.br/sonabra/pg_iframe.php?codEst=A304\&mesAno=2015

3. Calheiros, H. C., Gomes, M. R., \& Estrella, P. M. A. (2014). Calidad de las aguas meteóricas en la ciudad de Itajubá, Minas Gerais, Brasil. Ambiente \& Água-An Interdisciplinary Journal of Applied Science, 9(2), 336-346.

4. Camdessus, M., Badré, B., Chéret, I., \& Ténière-Buchot, P. F. (2005). Água: oito milhões de mortos por ano: um escândalo mundial. Rio de Janeiro: Bertrand.

5. Hagemann, S. E. (2009). Avaliação da qualidade da água da chuva e da viabilidade de sua captação e uso. (Dissertação de mestrado). Universidade Federal de Santa Maria, Santa Maria, RS, Brasil.

6. Lade, O., Oloke, D., Chinyio, E., \& Fullen, M. (2013). Potential for potable water savings by using rainwater: a case study of Ibadan, Nigeria. International Journal of Advancements in Research \& Technology, 2(4), 117-131.

7. Da Luz, L. A. R. (2005). A reutilização da agua: mais uma chance para nós. Rio de Janeiro: Qualitymark.

8. Melo, L. R. D. C. (2007). Variação da qualidade da água de chuva no início da precipitação. (Dissertação de mestrado). Universidade Federal do Rio Grande do Norte, Natal, RN, Brasil.

9. Parron, L. M., MUNIZ, D. H. D. F., \& Pereira, C. M. (2011). Manual de procedimentos de amostragem e análise físico-química da água. Colombo: EMBRAPA Florestas. 
10. Silva, V. N. D., \& Domingos, P. (2007). Captação e manejo de água de chuva. Saúde \& Ambiente em Revista, 2(1), 68-76.

11. Tomaz, P. (2003). Aproveitamento de água de chuva: para áreas urbanas e fins não potáveis. São Paulo: Navegar. 